\title{
Dynamic adaptive management for drinking water security in Kiribati
}

Presented at: Symposium on Climate Change Adaptation in the Pacific Region, Lautoka, Fiji, 26th-28 ${ }^{\text {th }}$ July 2016

Pierre Mukheibir (PhD, MSc)

Associate Professor

The Institute for Sustainable Futures, University of Technology Sydney

235 Jones Street Ultimo 2007, Australia

pierre.mukheibir@uts.edu.au

Lousie Boronyak-Vasco (BEcon and MEM)

Senior Research Consultant

The Institute for Sustainable Futures, University of Technology Sydney

235 Jones Street Ultimo 2007, Australia

louise.boronyak@uts.edu.au

Pelenise Alofa

Co-ordinator

Climate Action Network of Kiribati (KiriCAN)

PO Box 110, Bairiki, Tarawa, Kiribati

pelealofa13@gmail.com

The dynamic adaptive management process (DAMP) was designed to build the skills of community facilitators to lead participatory decision-making processes to plan for the delivery of basic services under a changing climate. It provides facilitators with a range of tools for leading conversations at the community level. It will also help to build skills and knowledge which will enable the community to participate in identifying solutions that are relevant and appropriate for their context.

The approach aims to build the adaptive capacity of communities in the outer islands of Kiribati to identify indicators/triggers, that draw upon various knowledge systems, including traditional knowledge, to define thresholds or limits to specific water related adaptation strategies. This will empower them to monitor adaptation strategies and subsequently contribute to the development of future adaptation strategies that will support the diversification of water resources.

This paper highlights the need for adaptive management of potable water supplies in Kiribati in the light of climate change impacts, It draws on the experience of the authors and outcomes of training workshops, and outlines a set of tools to:

- better understand the impacts of climate change on these possible water supply options

- $\quad$ identify triggers for when a new water option should be planned.

The tools and processes that are presented are flexible enough to be applied to a range of situations.

Key words: Adaptation, Kiribati, triggers, options, water, 
Page 1 


\section{Dynamic adaptive management for drinking water security in Kiribati}

\section{Introduction}

The remote Pacific Island nation of Kiribati is comprised of a group of 33 low lying coral atolls that are vulnerable to the impacts of climate change from variations in precipitation and rising sea levels (Tisdell, 2008). Kiribati is considered one of the least developed Pacific Islands with few natural resources. Economic development is hampered by a shortage of skilled workers, poor infrastructure and isolation from international markets.

Kiribati has an average elevation of less than two metres above sea level exposing the local water resources of communities across Kiribati to saltwater intrusion into groundwater resulting from frequent coastal inundation and accelerated coastal erosion caused by sea level rise and the increased frequency of storms and tropical cyclones (Tisdell 2008). This makes the water unfit for people to drink and bathe, increases the risk of epidemics, and reduces potential agricultural yields. Such effects place additional strain on people's livelihoods and wellbeing (economic security, health, infrastructure etc.) (Kuruppu 2009; de Freitas et al. 2013). Illnesses such as diarrhoea and pneumonia are the leading causes of death in Kiribati and are strongly related to poor hygiene from limited access to potable water and a lack of sanitation facilities (White et al. 2008).

These impacts are likely to be compounded by the projected impacts of climate change that will likely have a negative effect on both the quantity and quality of groundwater resources through variations in precipitation and rising sea level (White et al. 2007; Kuruppu \& Liverman 2011). Recently the Government of Kiribati operationalised various national adaptation programmes in which the water sector has been identified as a vulnerable sector to climate change impacts (PCCSP 2011b).

\section{Aim of this paper}

Adaptation is a continuous, ever-changing process involving cycles of decision making, planning, action, observation, and above all, social learning and continuous adjustment (Biggs et al. 2011; Moser \& Ekstrom 2010; Wild et al. 2015). Central to adaptation planning and implementation is the enhancement of adaptive capacity of systems. Adaptive capacity is defined by "the set of resources (natural, financial, institutional or human, access to ecosystems, information, expertise, and social networks) available for adaptation, as well as the ability of that system to use these resources effectively in the pursuit of adaptation," (Brooks \& Adger 2004, p.168). However, there are various limits and thresholds to adaptive capacity under certain dynamic climate and socio-economic scenarios (Adger et al. 2008). It is vital to identify these limits so that existing adaptation pathways can be revised and inform new adaptation strategies that are locally driven and owned.

In 2015, USAID through its Pacific-American Climate Fund (PACAM), funded the project Supporting community adaptation to water shortages in Kiribati. The research project aims to build the capacity of communities on two outer islands of Kiribati to identify and develop adaptation strategies that will support the diversification of water resources to ensure sufficient clean water is provided under a changing climate. 
Therefore this paper firstly sets out the need for an adaptation management approach for potable water supplies, and secondly, demonstrates a set of tools for facilitating a dynamic planning approach at the community level that is guided by observed triggers of change. Given that there are often competing objectives and preferences when selecting a viable supply option, the paper also outlines a simplified multi-criteria analysis process that can be undertaken at the community level.

\section{Methodology and capacity building approach}

The initial focus of the project was to train facilitators in the DAMP approach through a learning-by-doing approach. Facilitators from the KiriCAN network were trained by the project team from the Institute for Sustainable Futures (University of Technology Sydney) over two days in October 2015. This engagement provided valuable insights for the refinement of the processes, and provided worked examples based on local knowledge to be included in the resource materials. Specifically, the initial process for undertaking a weighted multi-criteria assessment proved quite complicated for some of the facilitators. This led to the development of a simplified approach, which was tested to good effect on the outer island training.

In March 2016, five of the trained facilitators put their skills into practice under the guidance of the ISF project team, and delivered training on two of the outer islands of Kiribati, Tabiteuea North and Abaiang. A total of 65 community members participated in the two day workshops run on each island. Again, this proved useful in two ways. Firstly the facilitators gained confidence in the tools and processes, secondly, they were able to adapt the illustrative examples to suit the local context.

A key output of the project is a facilitators handbook (in both English and iKiribati) to guide and support the facilitators on their future community engagements regards potable water supplies and climate change. The handbook has been finalised based on the practical lessons learned through the training events.

This process reinforces the importance of piloting and testing new concepts and processes in a collaborative manner, before distributing more widely.

A limitation of the paper and the project is that given the long time horizons for climate change, we are not able to measure the effectiveness of this process in terms of changes in how options are selected, and the timing of when decisions for new water supply options are made. Also, the project is midway through, and there will no doubt be further insights and lessons to be learned as the process is delivered to the other outer islands of Kiribati.

The emphasis of this project has been to empower local communities to make locally relevant decisions about their water supplies under climate change. However, the way that information flows down to these communities about climate change impacts, and how local decisions are then fed up the National government are not consistently understood. A social network analysis of the information flows and decision making are made is planned, but is not covered in this paper.

\section{Kiribati outer island domestic water supplies}

The World Health Organisation (Howard \& Bartram 2003) suggests the following volumes to meet the basic water needs per person per day:

- 5 litres for drinking (potable) 
- 15 litres for handwashing and basic food preparation (i.e. potable water)

- 20-30 litres for laundry and bathing

However, many rural communities on the outer islands lack access to adequate secure and safe sources of water (National Statistics Office 2012). More than two thirds of the households on the outer islands do not have access to protected sources of drinking water viz., protected wells or rainwater tanks. None have piped water from centralised systems and rely on open wells, rainwater catchments or village scale solar water pumped systems (NSO 2012). Open wells are those without lids and thus left open all the time while closed wells comprise those that have lids or have been closed off. With the introduction of pumping and piping systems, wells are closed once pumps and piping systems have been installed..

Thus, there are distinct challenges and deprivations related to water security that curtail livelihood choices such as small-scale agricultural practices or small business opportunities (Kuruppu 2009). They also widen existing gender inequalities as women and girls may have to invest greater time accessing clean potable water, limiting time spent on livelihood and educational activities; and drive processes such as migration to urban centres to access reliable infrastructure services (Connell 2011; Kuruppu \& Willie 2015).

\section{Historical and projected climate change in Kiribati}

Many of the impacts of climate change will be experienced by communities as changes in the hydrological cycle; and will exacerbate existing stresses on water resources (pollution, population growth) (Pahl-Wostl \& Knieper 2014; Mukheibir 2010).

In the Gilbert Islands, the average recorded temperatures have increased by $1{ }^{\circ} \mathrm{C}$ from 1950 to 2009 , while maximum temperatures have increased by $0.18^{\circ} \mathrm{C}$ per decade over the past 60 years (PCCSP 2011b).

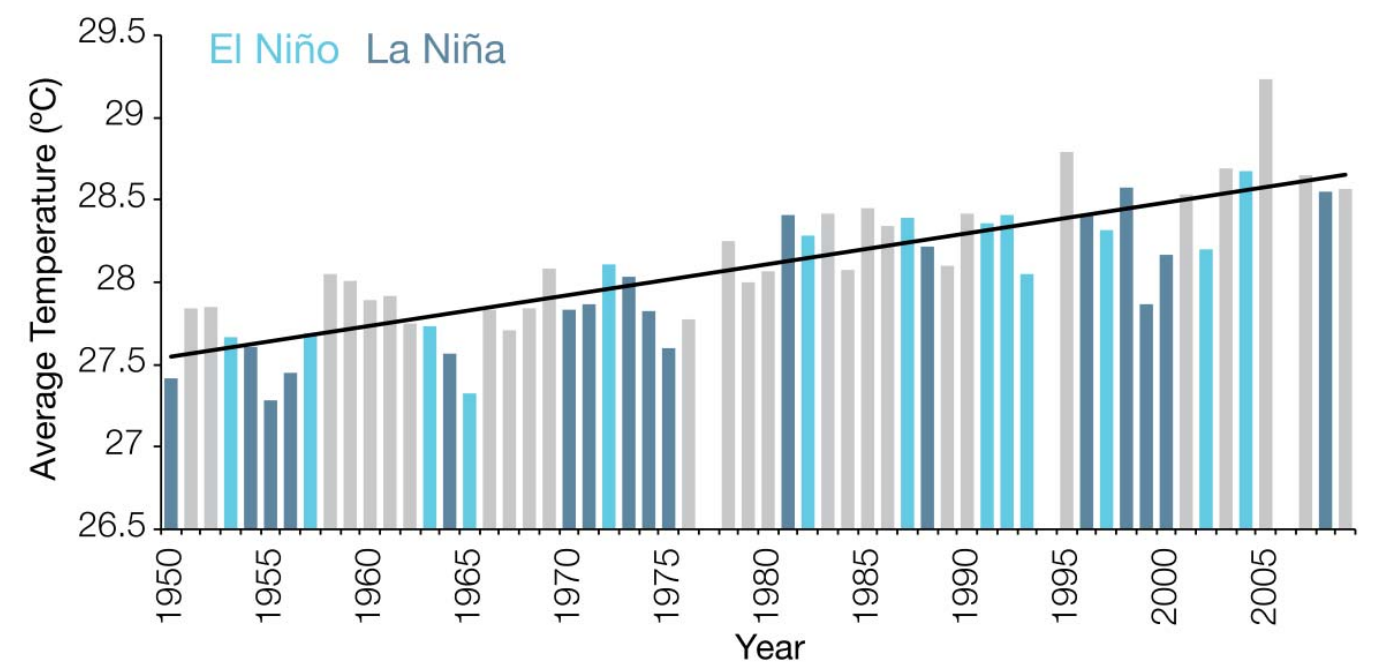

Figure 1 Average annual temperatures (PCCSP 2011b)

While annual rainfall in the Gilbert Islands can be described as highly variable, due mainly to El Nino and La Nina events, a gradual increase in rainfall can be observed for the traditionally wet seasons (PCCSP 2011b). The average rainfall is approximately $2100 \mathrm{~mm}$ with just over $900 \mathrm{~mm}$ received between May and October. 


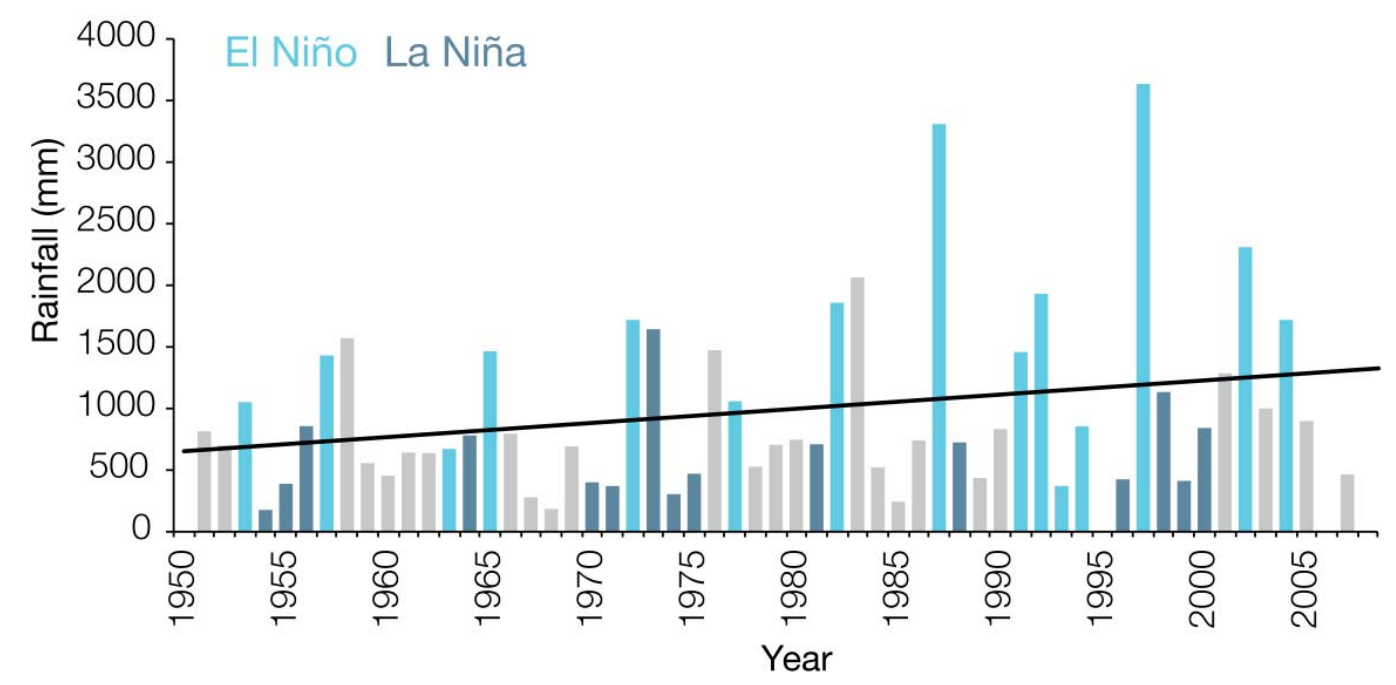

Figure 2: Average annual rainfall (PCCSP 2011b)

Melting ice in the polar regions and snow-capped mountains due to the increase in temperature has led to a global increase in the sea level. At the Gilbert Islands the sea level has risen by 1 to $4 \mathrm{~mm}$ per year since 1993 - 10-40mm per decade (PCCSP 2011b).

Future climate change scenarios for Kiribati are based on projections undertaken by the Pacific Climate Change Science Program (PCCSP 2011b), using 18 different models that best represent the climate of the western tropical Pacific region, specifically the Gilbert Islands.

The projections for Kiribati are based on three of the IPCC emissions scenarios for the periods around 230 and 2055 (IPCC 2007):

- Low impact on GHG emissions (B1) - due to a rapid change in economic structures toward a service and information economy, with reductions in material intensity, and the introduction of clean and resource-efficient technologies.

- Medium impact on GHG emissions (A1B) - due to very rapid economic growth, global population that peaks in mid-century and declines thereafter, and the rapid introduction of new and more efficient technologies, with a balance of between fossil and non-fossil energy sources.

- High impact on GHG emissions (A2) - due to continuously increasing global population and per capita economic growth and technological change are more fragmented and slower than in other scenarios.

Under these scenarios, the following changes can be expected:

\section{Temperature increase:}

Table 1: Projected annual average temperature increase (in ${ }^{\circ} \mathrm{C}$ ) for the Gilbert Islands (PCCSP 2011a)

\begin{tabular}{|l|c|c|c|c|c|c|}
\hline Scenarios: & $\begin{array}{c}\mathbf{1 9 9 0} \\
\text { (baseline) }\end{array}$ & $\begin{array}{c}\mathbf{2 0 1 5} \\
\text { (calculated) }\end{array}$ & $\begin{array}{c}\mathbf{2 0 3 0} \\
\text { (projected) }\end{array}$ & $\begin{array}{c}\mathbf{2 0 4 5} \\
\text { (calculated) }\end{array}$ & $\begin{array}{c}\mathbf{2 0 5 5} \\
\text { (projected) }\end{array}$ & $\begin{array}{c}\mathbf{2 0 9 0} \\
\text { (projected) }\end{array}$ \\
\hline Low (B1) & 0 & 0.4 & 0.7 & 1.1 & 1.3 & 1.7 \\
\hline $\begin{array}{l}\text { Medium } \\
\text { (A1B) }\end{array}$ & 0 & 0.4 & 0.8 & 1.3 & 1.6 & 2.6 \\
\hline High (A2) & 0 & 0.4 & 0.8 & 1.3 & 1.6 & 3.0 \\
\hline
\end{tabular}


The medium and high scenarios are similar in the early to midterm years, with the higher scenario ending up with a higher average temperature increase by 2090 , accompanied by a rise in the number of hot days and warm nights and a decline in cooler weather.

\section{Rainfall increase:}

The projected average annual rainfall is projected to increase (and across the wet and dry seasons), with droughts projected to become less frequent (PCCSP 2011b). However, extreme rainfall days are expected to occur more often.

Table 2: Projected average rainfall increase (as percentage change) for the Gillbert Islands (PCCSP 2011a)

\begin{tabular}{|l|c|c|c|c|c|c|}
\hline Scenarios: & $\begin{array}{c}\mathbf{1 9 9 0} \\
\text { (baseline) }\end{array}$ & $\begin{array}{c}\mathbf{2 0 1 5} \\
\text { (calculated) }\end{array}$ & $\begin{array}{c}\mathbf{2 0 3 0} \\
\text { (projected) }\end{array}$ & $\begin{array}{c}\mathbf{2 0 4 5} \\
\text { (calculated) }\end{array}$ & $\begin{array}{c}\mathbf{2 0 5 5} \\
\text { (projected) }\end{array}$ & $\begin{array}{c}\mathbf{2 0 9 0} \\
\text { (projected) }\end{array}$ \\
\hline $\begin{array}{l}\text { Annual: } \\
\text { Low (B1) }\end{array}$ & 0 & 9 & 14 & 18 & 20 & 25 \\
\hline $\begin{array}{l}\text { Medium } \\
\text { (A1B) }\end{array}$ & 0 & 8 & 12 & 19 & 23 & 37 \\
\hline High (A2) & 0 & 4 & 7 & 17 & 23 & 42 \\
\hline $\begin{array}{l}\text { Wet season: } \\
\text { Low (B1) }\end{array}$ & 0 & 6 & 10 & 12 & 14 & 19 \\
\hline $\begin{array}{l}\text { Medium } \\
\text { (A1B) }\end{array}$ & 0 & 6 & 10 & 15 & 18 & 30 \\
\hline High (A2) & 0 & 3 & 5 & 13 & 18 & 30 \\
\hline $\begin{array}{l}\text { Dry season: } \\
\text { Low (B1) }\end{array}$ & 0 & 11 & 18 & 24 & 28 & 34 \\
\hline $\begin{array}{l}\text { Medium } \\
\text { (A1B) }\end{array}$ & 0 & 9 & 15 & 24 & 30 & 50 \\
\hline High (A2) & 0 & 8 & 12 & 23 & 31 & 57 \\
\hline
\end{tabular}

\section{Sea level rise:}

The sea level is expected to continue to rise in Kiribati, with seasonal fluctuations, resulting in increases in storm surges and coastal flooding.

Table 3: Projected annual average sea level increase (in $\mathrm{m}$ ) for the Gilbert Islands (PCCSP 2011a)

\begin{tabular}{|l|l|l|l|l|l|l|}
\hline & $\begin{array}{l}\mathbf{1 9 9 0} \\
\text { Scenarios: }\end{array}$ & $\begin{array}{l}\mathbf{2 0 1 5} \\
\text { (calculated) }\end{array}$ & $\begin{array}{l}\mathbf{2 0 3 0} \\
\text { (projected) }\end{array}$ & $\begin{array}{l}\mathbf{2 0 4 5} \\
\text { (calculated) }\end{array}$ & $\begin{array}{l}\mathbf{2 0 5 5} \\
\text { (projected) }\end{array}$ & $\begin{array}{l}\mathbf{2 0 9 0} \\
\text { (projected) }\end{array}$ \\
\hline Low (B1) & 0 & 0.06 & 0.09 & 0.16 & 0.17 & 0.31 \\
\hline $\begin{array}{l}\text { Medium } \\
\text { (A1B) }\end{array}$ & 0 & 0.06 & 0.09 & 0.17 & 0.20 & 0.38 \\
\hline High (A2) & 0 & 0.06 & 0.09 & 0.17 & 0.19 & 0.39 \\
\hline
\end{tabular}




\section{Impact of climate change on water resources}

The following impact map shows how the projected changes may impact the supply and quality of water resources and demand on the Gilbert Islands in the manner described below.

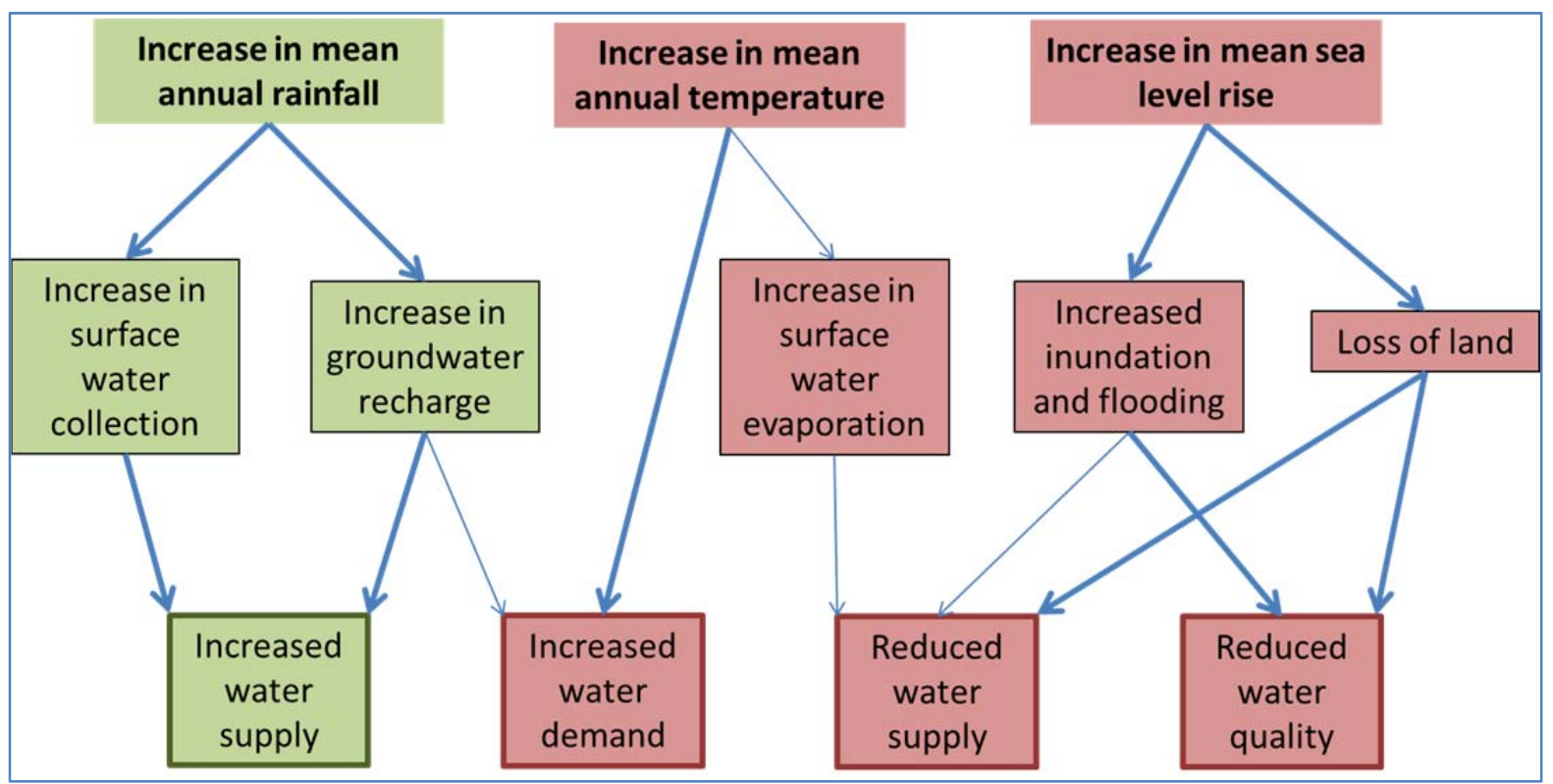

Figure 3: Climate change impacts on water resources

\section{Increase water supply:}

With the projected increase in mean annual rainfall and the decline in drought events, both surface water and groundwater will be frequently replenished. This will in turn provide a positive impact on domestic water availability through both rainwater tanks and groundwater abstraction. If average rainfall increased by $7 \%$, the groundwater recharge is estimated to increase by $5.5 \%$ (in contrast, a $10 \%$ decline in rainfall may cause a $14 \%$ reduction in groundwater recharge) (World Bank 2000).

\section{Reduced water supply:}

Climate change is expected to reduce water supplies in the Pacific to the point where supplies may be insufficient to meet demand during low rainfall periods (IPCC, 2007). Under a warming climate it is likely that evapotranspiration would increase, but its effects on groundwater recharge would be much milder than the effect of changes in rainfall. The relatively large projected increases in rainfall that are projected for the islands near to the equator, exceed the smaller changes in potential evapotranspiration. A theoretical $10 \%$ increase in annual evapotranspiration could result in as much as a $6 \%$ decline in groundwater recharge (World Bank 2000). Higher projected temperatures will result in increased evaporation of surface water, but since freshwater lakes and dams are not a feature of water resource management in these islands, this should not be a concern.

A rise in sea level of 0.4 meters (the worst-case scenario in 2090) would have little effect on the groundwater supply and could possibly even raise its volume, as the groundwater table (the top of the freshwater lens) would tend to rise while its base remained relatively unaffected. However, if the width of the islands were reduced by inundation and erosion, which is likely, the thickness of the groundwater could decline by as much as $29 \%$ (World Bank 2000, p24). 


\section{Reduced water quality:}

The effects of extreme events on the water supply could be significant. Currently, high sea levels during El Nino years can lead to seawater contamination of freshwater lenses. However, recovery is generally rapid due to the accompanying high rainfall. The higher overtopping and inundation that may occur in the future, however, could considerably increase the risks of saline contamination (World Bank 2000).

\section{Increased water demand:}

The increase in average and extreme temperatures will likely increase the demand for water for drinking and cooling, although this is not considered to be significant. The increased availability of water due to the increased average annual rainfall, could result in an increase in the demand for water due to it's perceived abundance, with competing demands over potable water for domestic uses versus agricultural initiatives.

\section{Responding using the dynamic adaptive management process (DAMP)}

In order to respond to these potential changes in the supply and demand (of which their timing and magnitude are uncertain), accessible tools and processes are needed at the community and local government level.

The dynamic adaptive management process was designed to enable planners, as well as community leaders and members to understand the triggers that indicate the need for a new adaptive response under a range of possible future climate and risk scenarios (Mukheibir 2007). These future scenarios are not static, but are continuously changing (dynamic) and hence need to be constantly redescribed, and the effectiveness of the response options reassessed (Haasnoot et al. 2013). Therefore, strategic indicators or triggers play a key role in evaluating whether a response option/s is not performing as was originally planned, necessitating a switch to a different option/s pathway to avoid water shortages.

The approach and tools have been designed in such a way that they provide practitioners with the knowledge to undertake dynamic planning under uncertainty. Special care was taken to ensure that they are simple enough for community leaders and members to understand and follow.

The impacts of climate change will be felt at the local level, therefore it is important that any adaptation plan be managed at a local level by those directly affected by the outcomes, since the changes in the initial assumptions are best assessed locally (Pahl-wostl et al. 2007). The responses should be needs-driven from the community level, taking cultural values and gender issues into consideration (Kuruppu 2009). The integration of indigenous knowledge and practices in the information and thinking processes is equally important. In Kiribati, Village Water Committees (VWC) have been established to provide local input and guidance on water issues. The VWC attempt to have gender equity to ensure that women are directly engaged in the process.

The DAMP approach has been broken down into three stages:

1) Creating a hierarchy of responses and options: The first step in process is to identify a set of viable adaptation responses that satisfy both the water demand needs as well as the socio-economic considerations of the local community - this is best done using multicriteria analysis (MCA). The process for assessing the adaptation options against multicriteria involves: confirming the water policy objectives, defining the problem due to 
climate change, assessing other uncertainties and risks, and collaboratively agreeing upon a meaningful set of criteria for assessment of the proposed options.

The assessment criteria can be drawn from social, technical, environmental, economic and political (STEEP) considerations, and should be closely linked to the community values and water policy objectives. The set of criteria should be a combination of qualitative and quantitative and could include public acceptability, impact on water quality, complexity of the option, energy intensity, and employment generation potential (Mukheibir 2007).

The number of criteria should be kept to a minimum, but should be sufficiently comprehensive i.e. the set of criteria should comprise the number of specific criteria that is just good enough to distinguish between the options. The criteria should be selected with consideration of the available data. The criteria should not require too many assumptions about the future or lead to second-guessing. Double counting of two similar or related benefits should also be avoided, such as accounting for both energy efficiency as well as GHG reductions for example (Mukheibir \& Mitchell 2011).

Assigning a relative preference weighting to the criteria is a key component of the MCA process. If we consider all the criteria as having equal importance, less important criteria will have undue influence over which of the options is judged the best. Therefore, it is useful to prioritise the criteria from most preferred to least preferred, and to assign a weighting based on the number of votes they receive from the participants. Weighting a criterion means making a value-based decision as to how important it is in relation to each of the other criteria.

The second step in this process is to generate a list of options and arrange them in a hierarchy of more preferred to least preferred. Both supply and demand side options should be considered that account for both technical and social factors. However, reducing demand to below the basic minimum daily volume should not be encouraged. Options that don't meet the supply volume or water quality objectives should not be considered as viable supply options.

In order to keep the process as simple as possible, a relative ranking of all the options' performance against each criterion should be agreed by all the participants. The ranking of options against the criteria is best done through group consensus and discussion. The collective score for each option will be calculated using a weighted summation of the criteria ratings using simple arithmetic.

The options are then arranged in a hierarchy from most favourable to least favourable. The most favourable scoring option will be considered first to close the current or future gap between supply and demand. Followed by the next option, until the objective is met.

Potential responses to climate impacts could include:

- Rainwater collection could be promoted by fitting new buildings with underground cisterns and encouraging all new houses to be fitted with rainwater storage.

- Protected wells to avoid contaminating potentially good clean water.

- Consider sanitation options that do not contaminate the already limited clean potable water.

- Groundwater recharge by building swales to capture large downpours of water and give it time to seep into the ground before running off to ocean. 
- Desalination should be considered only when rainwater or groundwater sources are insufficient, as the cost remains high. Future technological breakthroughs may help make desalination more affordable.

- Water importation is not considered a viable alternative due to the high costs and shipping risks.

2) Identifying triggers and indicators: The outcome of this stage of the tool is a range of indicators to provide an early warning of when the objectives are not being met - for example these may include low groundwater levels, high salinity levels in the aquifer, calcification of cooking pots, unreliable rainwater supplies, some health related indicators, high cost of providing water due to high fuel prices for pumping etc. Due to future uncertainties even the best laid plans may be confronted by a new set of risks that require a new adaptive response. The type and timing of the options to be deployed will depend on the climate and risk scenario that unfolds at that time. Indicators provide the community (and local government officials) with signs that will trigger deployment of the next best option to ensure that the water supply objectives are being met.

The impact diagram (shown in Figure 4) allows participants to map the connections between impacts and influences, and to identify critical indicators of change that would facilitate early warning of a supply-demand imbalance. It is ideal for understanding how climate variability and extreme events (such as big storms) will affect water resources and the subsequent cascade of impacts resulting in poor community health. Figure 4 that illustrates the impacts due to decreasing rainfall and the associated indicators (written in red).

For each trigger, it is important to agree on the threshold triggers for each impacts that would indicate that an option is not meeting its supply objective (volume), cost threshold, or other social requirements (e.g. salinity level of the water), and who would be in a position to observe and report on these changes. It may be the nurse at the local clinic who keeps a record of the cases of diarrhoea, and when this reaches a threshold of 10 per week, he or she is required to report that to the Department of Health. Using technical assessments in remote communities is often not feasible due to the lack of technical capability and equipment. Therefore the inclusion of local knowledge in this step is important, since it is the community members themselves who will be monitoring the effectiveness of the options under changing conditions. 


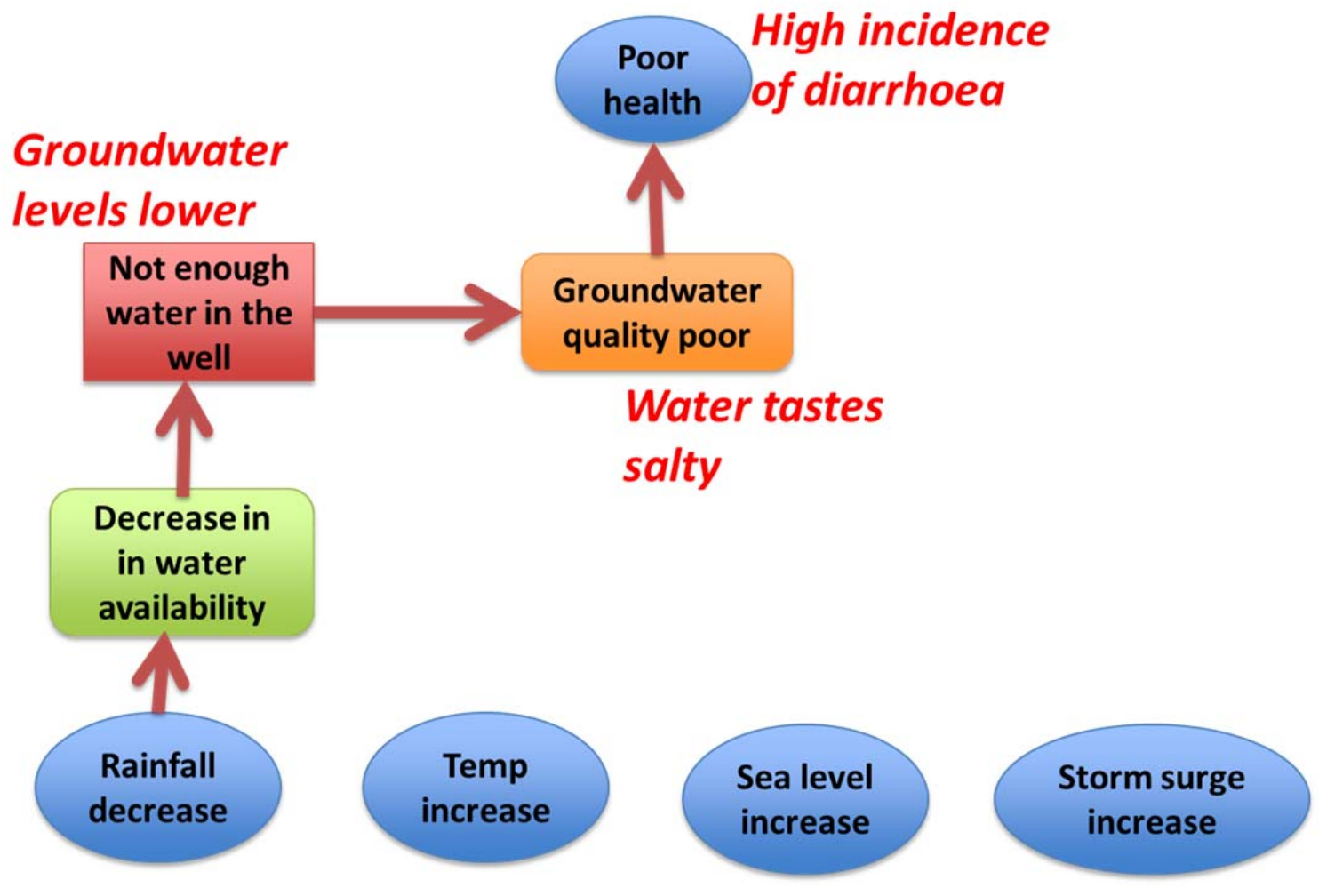

Figure 4: Example of an impact map with indicators for rainfall decrease

3) Testing against climate and risk scenarios: To identify what sequence of the options that would best suit the local situation under potential future risks, two possible climate scenario were used - a drying scenario and a wetting scenario. This was to ensure that the participants recognised that different adaptation management pathways would be needed to provide a resilient water supply system under different futures.

When an indicator exceeds the acceptable level, this acts as a trigger for planning for the next-best response option (in this case a drinking water supply option). If at a later date an indicator for the new supply option exceeds an acceptable level, the process is repeated to identify the next best water supply option under the prevailing conditions.

The process is best illustrated by the example shown in Figure 5. Starting with the option of a hand dug well at the home, participants consider the likely impacts (shown in the pink square) due to an increase in storm surges (with inundation and erosion) and their associated indicators (the green square). The indicators provide a signal for the need to select a new drinking water supply option. They then choose a new option from the prioritised list of options and the process is then repeated under further impacts due to rainfall decrease, for example. 


\section{Impacts Options Indicators}

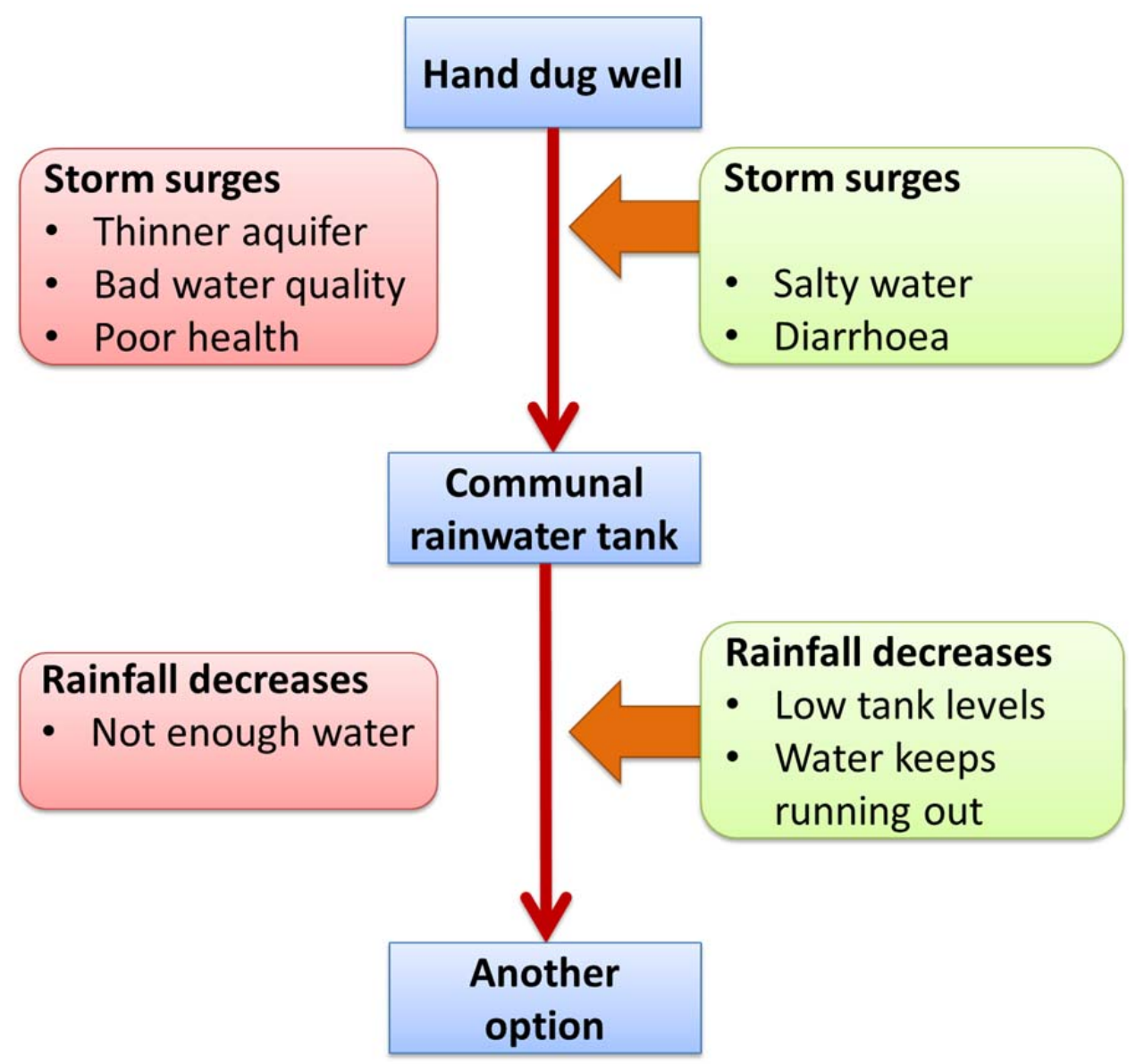

Figure 5: Mapping the new responses to the impacts and indicators

\section{Outcomes}

The participants from the two workshops generated a very similar comprehensive list of future water supply options, which also included options which would not satisfy the volume and quality objectives - these have been indicated with an X, in Table 4. These options were not considered further.

Table 4: Master list of viable water supply options identified for Kiribati

\begin{tabular}{|ll|}
\hline No. & Water supply option \\
\hline $\mathbf{1}$ & Communal rainwater tank/s \\
\hline $\mathbf{2}$ & Desalination \\
\hline $\mathbf{3}$ & Household rainwater tank \\
\hline $\mathbf{4}$ & Inland groundwater well \\
\hline $\mathbf{5}$ & Solar water pump (inland) \\
\hline $\mathbf{6}$ & Catch rainwater with palm leaves \\
\hline $\mathbf{7}$ & Bring water to parts of the island by boat \\
\hline
\end{tabular}




\begin{tabular}{|llc|}
\hline $\mathbf{8}$ & Collecting water from the swamp & $\mathrm{X}$ \\
\hline $\mathbf{9}$ & Handpump on an inland well & \\
\hline $\mathbf{1 0}$ & Moimoto (coconut water) & $\mathrm{X}$ \\
\hline $\mathbf{1 1}$ & Protected household well & \\
\hline $\mathbf{1 2}$ & Rainwater harvesting using a bucket and guttering & $\mathrm{X}$ \\
\hline
\end{tabular}

Similarly, the two workshops generated quite similar sets of criteria for ranking the options. Criteria such as enough water and good quality water were not considered as good criteria, since they were the objectives, and hence were not discerning enough, because all the options would need to meet such an objective. The criteria that consistently scored highly were Affordability, Reliability, Ease of maintenance, Safe for the environment, and Accessibility.

The process for mapping the impacts and associated indicators under the two scenarios revealed insights for the participants. Specifically, that if the rainfall was decreasing over time, it made little sense to augment the communal raintanks that were often empty with household raintanks. But rather an option that was not rain dependent should be sought. Similarly, if the groundwater was salty due to sea level rise, then sealing the well and placing a handpump on it was also not the answer, but to perhaps look inland or consider a rainwater tank.

The sequence of moving from a simple well, to a protected well to address storm surges, and to then to move to rainwater tanks if the groundwater became too salty was novel for the participants, but by the end of the workshop clearly understood.

All the participants agreed that the use of desalination was a last resort, and would depend on the availability of parts and technical skills in Kiribati.

\section{Conclusion}

This paper has demonstrated the importance of a dynamic adaptation approach in two ways. Firstly, in developing the tools and processes, the research team adapted the materials after each engagement session, resulting in a more appropriate and relevant set of guidance materials. A learning-by-doing approach also allowed the facilitators to have a sense of ownership of the tools. Ongoing support for the facilitators is important both for the understanding of the issues and for their confidence to deliver the workshops.

Secondly, this process of constantly reviewing the impact of climate change on water supplies and monitoring the indicators and thresholds, and then deciding if a new option is needed can be called a Dynamic Adaptive Management Process. By regularly reviewing how their supply options are functioning under changing conditions, communities will be able to plan adaptive responses to any adverse changes in a timely manner.

Working at the community level reveals insights for the facilitators who are made aware of the what is important for local communities when reviewing various water supply options, Insights are also revealed for the community members about how climate change might affect their water supplies, and also about how a hierarchy of options might be deployed under various unfolding futures. 
The challenge will then be to leverage sufficient capital to build the necessary infrastructure, and to ensure the necessary technical skills are provided and retained on the islands where it will be needed to avoid water storages into the future.

Further work is needed to understand the flow of information and the decision making dynamics between community based organisations and government department charged with delivering sustainable water supplies. This is important if there is to a transparent planning response to the impact of climate change on potable water supplies. 


\section{References:}

Adger, N., Dessai, S., Goulden, M., Hulme, M., Lorenzoni, I., Nelson, D.R., Naess, L.O., Wolf, J. \& Wreford, A., 2008. Are there social limits to adaptation to climate change? Climatic Change, Springer, 93(3-4), pp.335-354.

Biggs, C., Edwards, T., Rickards, L. \& Wiseman, J., 2011. Scenario planning for climate adaptation, Victorian Centre for Climate Change Adaptation Research, Australia.

Brooks, N. \& Adger, N., 2004. Technical Paper 7: Assessing and Enhancing Adaptive Capacity. In B. Lim \& E. Spanger-Siegfried, eds. Adaptation Policy Framework for Climate Change. Cambridge, UK: Cambridge University Press, pp. 165-182.

Connell, J., 2011. Elephants in the Pacific? Pacific urbanisation and its discontents. Asia Pacific Viewpoint, John Wiley and Sons, 52(2), pp.121-135.

de Freitas, C.R., Helbig, M. \& Matzarakis, A., 2013. Hydroclimatic assessment of water resources of low Pacific islands: evaluating sensitivity to climatic change and variability. International Journal of Climatology, John Wiley and Sons, 34(3), pp.881-892.

Haasnoot, M., Kwakkel, J.H., Walker, W.E. \& ter Maat, J., 2013. Dynamic adaptive policy pathways: A method for crafting robust decisions for a deeply uncertain world. Global Environmental Change, Elsevier, 23(2), pp.485-498.

Howard, G. \& Bartram, J., 2003. Domestic Water Quantity, Service Level and Health: Executive summary, World Health Organisation, Geneva, Switzerland.

IPCC, 2007. Climate Change 2007: Impacts, Adaptation and Vulnerability. Working Group II Contribution to the Intergovernmental Panel on Climate Change Fourth Assessment Report, Geneva: IPCC.

Kuruppu, N., 2009. Adapting water resources to climate change in Kiribati: the importance of cultural values and meanings. Environmental Science \& Policy, Eslevier, 12(7), pp.799809.

Kuruppu, N. \& Liverman, D., 2011. Mental preparation for climate adaptation: The role of cognition and culture in enhancing adaptive capacity of water management in Kiribati. Global Environmental Change, Elsevier, 21(2), pp.657-669.

Kuruppu, N. \& Willie, R., 2015. Barriers to reducing climate enhanced disaster risks in Least Developed Country-Small Islands through anticipatory adaptation. Weather and Climate Extremes, Elsevier, 7, pp.72-83.

Moser, S. \& Ekstrom, J., 2010. A framework to diagnose barriers to climate change adaptation. Proceedings of the National Academy of Sciences of the United States of America, PNAS, 107(51), pp.1-6.

Mukheibir, P., 2007. Qualitative assessment of municipal water resource management strategies under climate impacts: The case of the Northern Cape, South Africa. WaterSA, Water Research Commission of South Africa, 33(4), pp.575-582.

Mukheibir, P., 2010. Water access, water scarcity, and climate change. Environmental management, Springer, 45(5), pp.1027-39.

Mukheibir, P. \& Mitchell, C., 2011. Planning for resilient water systems - a water supply and demand investment options assessment framework [prepared for the Smart Water Fund], Institute for Sustainable Futures, University of Technology, Sydney, Australia. 
National Statistics Office, 2012. Kiribati 2010 Census of population and Housing: Volume 1 basic Information and Tables, Ministry of Finance, Bairiki, Tarawa.

NSO, 2012. Report on the Kiribati 2010 Census of Population and Housing, National Statistics Office, Ministry of Finance and Economic Planning, Bairiki, Kiribati.

Pahl-Wostl, C. \& Knieper, C., 2014. The capacity of water governance to deal with the climate change adaptation challenge: Using fuzzy set Qualitative Comparative Analysis to distinguish between polycentric, fragmented and centralized regimes. Global Environmental Change, Elsevier, 29, pp.139-154.

Pahl-wostl, C., Sendzimir, J., Jeffrey, P., Aerts, J., Berkamp, G. \& Cross, K., 2007. Managing Change toward Adaptive Water Management through Social Learning. Ecology And Society, 12(2), p.30.

PCCSP, 2011a. Climate Change in the Pacific: Scientific Assessment and New Research | Volume 2: Country Reports, Pacific Climate Change Science Program, Department of the Environment, Australia.

PCCSP, 2011b. Current and future climate of Kiribati Kiribati 's current climate, Pacific Climate Change Science Program, Department of the Environment, Australia.

Tisdell, C., 2008. Global warming and the future of Pacific Island countries. International Journal of Social Economics, Emerald Group Publishing Ltd 35(12), pp.889-903.

White, I., Falkland, T., Metutera, T., Katatia, M., Abete-Reema, T., Overmars, M., Perez, P. \& Dray, A., 2008. Safe water for people in low , small Island Pacific Nations : The ruralurban dilemma. Development, Cambridge, 51, pp.282-287.

White, I., Falkland, T., Perez, P., Dray, A., Metutera, T., Metai, E. \& Overmars, M., 2007. Challenges in freshwater management in low coral atolls. Journal of Cleaner Production, Elsevier, 15(16), pp.1522-1526.

Wild, L., Booth, D., Cummings, C., Foresti, M. \& Wales, J., 2015. Adapting development: Improving services to the poor, Overseas Development Institute, London.

World Bank, 2000. Cities, Seas, and Storms: Managing change in Pacific island economies, Volume IV, Adapting to Climate Change, The World Bank, USA. 